\title{
Research on Composite Braking Technology for Electric Drive High Speed Tracked Vehicle
}

\author{
Hui SHENG ${ }^{1, a}$, Chun-Ming LI ${ }^{1}$,Yan XU' ${ }^{2}$, Ming-Gang DU ${ }^{1}$, Tian $\mathrm{MA}^{1}$ \\ ${ }^{1}$ China North Vehicle Research Institute Science and Technology on Vehicle Transmission \\ Laboratory, Beijing, China \\ ${ }^{2}$ China Academy of Ordnance Science, Beijing, China \\ ashenghui0419@163.com
}

\begin{abstract}
Keywords: Electric drive, High speed tracked vehicle, Composite braking, Fuzzy control, Dynamic coordinated control, Real time simulation.
\end{abstract}

\begin{abstract}
In order to solve that the single execution component and mechanics-motor composite braking cannot meet the braking requirement of electric drive high speed tracked vehicle, the method of mechanical brake, motor and electro hydraulic retarder composite braking is proposed. Through the analysis of the mechanical brake, motor and electro hydraulic retarder braking characteristics, the steady braking force distribution control strategy based on fuzzy control and the dynamic coordinated control strategy have been proposed; the model of simulation was built in Mat lab/Simulink and real time simulation system RT-LAB was using to establish the "Driver-controller" in ring real time simulation system of electric drive high speed tracked vehicle and the verification of simulation experiment was carried out. The results show that the system can well meet the braking requirement of the electric drive high speed tracked vehicle and the control strategy proves the feasibility of control algorithm, which provides a theoretical basis for the research of high speed braking of the tracked vehicle.
\end{abstract}

\section{Introduction}

The electric drive technology is an important research direction of the tracked vehicle propulsion system. With the development of high speed, heavy load and automation, the vehicle has put forward higher and higher requirements on the stability, reliability, controllability and maneuverability of the vehicle braking system. The single execution component is difficult to meet the requirements of the braking ability of electric drive high speed tracked vehicle. Making use of a variety of execution components to ensure the braking performance of the vehicle braking is the future development direction of high speed track vehicle braking system.

Each of the literature [1-5] employs two execution components to form composite braking, which involves fewer brake parts, relatively simple control strategy, and did not take into account the influence on the braking performance of dynamic response process, using off-line simulation to validate the strategy. But the speed of electric drive high speed tracked vehicle which is higher than $80 \mathrm{~km} / \mathrm{h}$, the current literatures lack such high speed braking research. So electric drive high speed tracked vehicle mechanics-motor-retarder composite braking fuzzy control strategy is proposed for the first time, namely to add electro hydraulic retarder which is new auxiliary braking device to traditional mechanics-motor composite braking system forming mechanics-motor-retarder composite braking; the three dynamic response time is considered generally and the fluctuation in the switching process of braking mode is reduced, at the same time the vehicle braking performance is improved. At last make use of real-time simulation to validate the strategy. The results show that the strategy meets the braking requirements and effectively improves the dynamic performance of the vehicle braking.

\section{Analysis of Mechanics-Motor-Retarder Composite Braking System}

According to the braking requirement of the high speed tracked vehicle, the designed mechanics- 
motor-retarder composite braking system is composed of mechanical brake, permanent magnet synchronous motor and electro hydraulic retarder.

The braking performance of mechanical brake at low speed is stable; the temperature of brake rises high when the speed of vehicle becomes fast, which will intensify abrasions and reduce braking efficiency [6].

The torque of permanent magnet synchronous motor is small when the speed is high, but it can realize energy recovery, and fast response; with the decline of speed in motor, braking torque is increasing; when the motor speed is reduced to a certain extent, restraint of the characteristics of the motor, braking torque is zero, but the speed is not zero, unable to realize the stop of vehicle [7].

Electro hydraulic retarder is a new auxiliary brake device for vehicle and has a large braking torque, small air loss torque, fast response of speed and other advantages. Mainly consists of the stator, a pair of salient pole rotor and the ring exciting coil. Salient pole rotor is $\mathrm{H}$ rotary table, and transmission device is attached to the output shaft; as an independent annular excitation coil, it is mounted on the inner side of the stator of retarder. Vehicle transmission output shaft drives retarder rotor rotating; when the vehicle is braking, battery of the vehicle provides current for the excitation coil of the retarder, generating a magnetic field; on the inner surface of retarder stator produces eddy current, resulting in brake torque, the heat generated can be cooled by water away [8]. Structure is shown in Fig. 1.

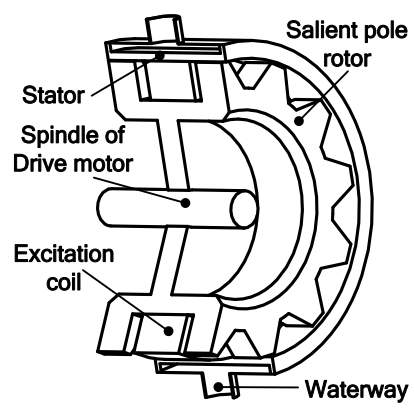

Fig. 1. Structure of Retarder

Electro hydraulic retarder and the transmission shaft is not directly contact in the braking process, so at high speed it can give priority to electro hydraulic retarder; when the speed of vehicle is low, the rotor speed of electro hydraulic retarder and the braking force is low; combining with the motor characteristics, at this time, when the vehicle needs further brake, the braking system needs intervention of mechanical brake to make the speed of vehicle step down to zero.

\section{Strategy of Mechanics-Motor-Retarder Composite Braking}

Considering the characteristics of three kinds of braking components, the speed and the angle of the pedal, the braking torque needed by motor is provided by the fuzzy control. When the power of motor required braking torque exceeds rated power, only to provide the braking torque under the rated power, the insufficient part is provided by the electro hydraulic retarder. Electro hydraulic retarder provides corresponding braking torque according to the current speed; when the sum of the motor braking torque and electro hydraulic retarder braking torque cannot meet the demand of total power, the rest is provided by the mechanical brake. If the speed is less than $10 \mathrm{~km} / \mathrm{h}$, the motor braking torque and electro hydraulic retarder braking torque are zero, and braking force is provided all by the mechanical brake. This will basically guarantee that the mechanical braking torque is equal to the difference of the total demand braking torque and the sum braking torque of the motor and electro hydraulic retarder every moment, making the braking deceleration felt by driver under certain input of the braking pedal is determined. In the end, the three control systems are dynamically coordinated and controlled by the feed forward and feedback control algorithm. Control strategy of composite braking system is shown in Fig. 2. 


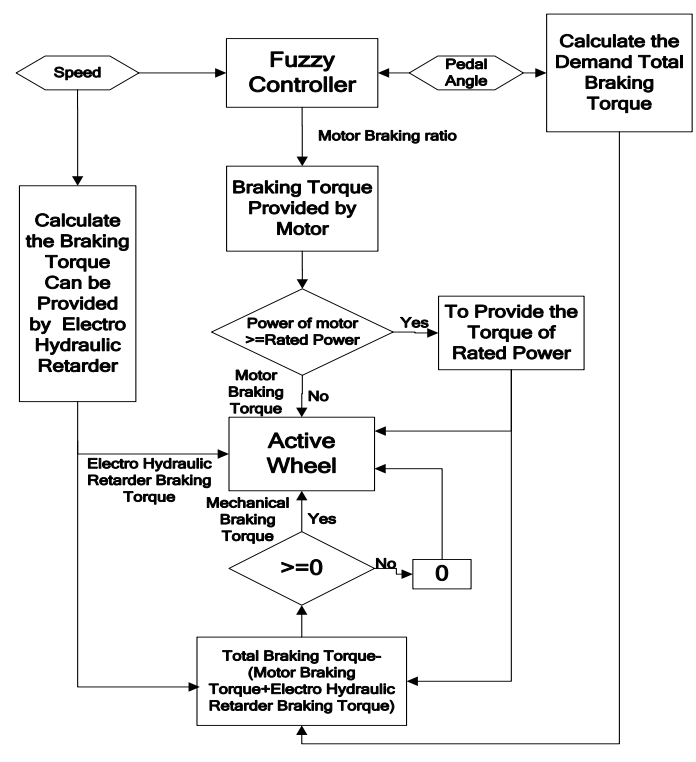

Fig. 2. Control Strategy of Composite Braking System

\section{Design of Fuzzy Logic Control Strategy}

The fuzzy control strategy is adopted by mechanics-motor-retarder composite braking, which is mainly based on the current state of the vehicle to assign the braking force ratio of motor. The speed and the angle of braking pedal are as the input variables of the controller, and the braking force ratio of the motor is as output variables of the controller, fuzzy control rules as follows: (1)low speed, the efficiency of generation of motor is very low in the situation of low speed and high torque [7], and the rotor speed of electro hydraulic retarder is low too, smaller braking force, the distribution ratio of the mechanical braking should be improved; (2)high speed, the motor is in constant power region; power of generation efficiency of the motor is relatively high at this time; power of generation efficiency of the motor is highest near the basic speed; in order to improve the braking energy recovery, in the vicinity of constant power area and the vicinity of base speed, should increase the proportion of motor braking; generally motor braking force cannot meet the demand, so it is necessary to use electro hydraulic retarder to meet the requirements of braking at the same time; (3)the emergency braking, to ensure the braking safety, the mechanical braking ratio should be improved, insufficient part is supplied by electro hydraulic retarder and motor. The basic process of fuzzy control is shown in Fig. 3.

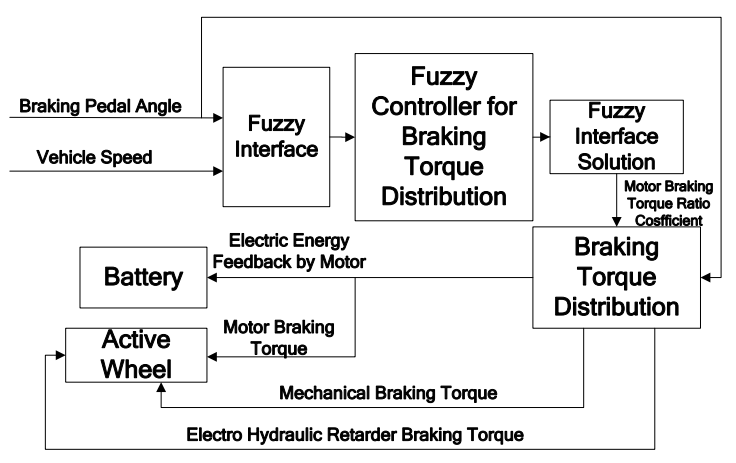

Fig. 3. Basic Process of Fuzzy Control

\section{The Design of Fuzzy Controller}

The basic theory of the input variable of vehicle speed is $[0,85]$, the basic theory of the brake pedal angle is $\left[0,45^{\circ}\right]$. The basic theory of the braking force ratio coefficient of motor as the output variable 
is $[0,1]$. Vehicle speed, brake pedal angle and the motor braking force ratio select high, middle, low three levels, and set up nine control rules; membership function select triangular and trapezoidal; each variable membership degree function is shown in Fig. 4 to Fig. 6. Fuzzy control rules are shown in Table 1.

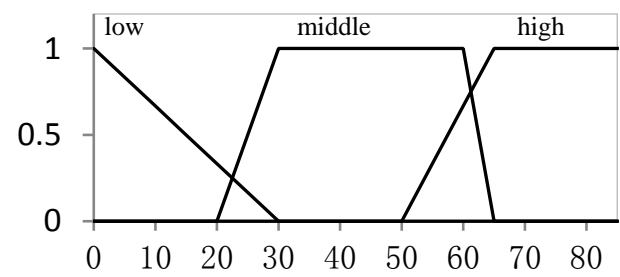

Fig. 4. Speed Membership Function

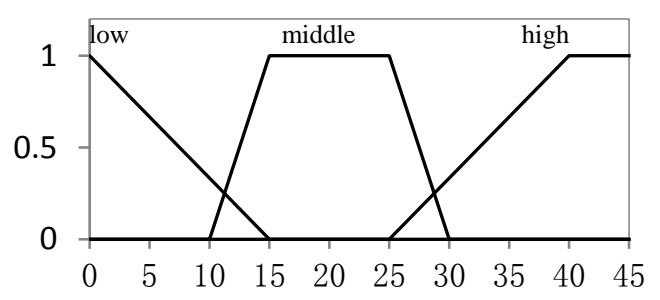

Fig. 5. Pedal Angle Membership Function

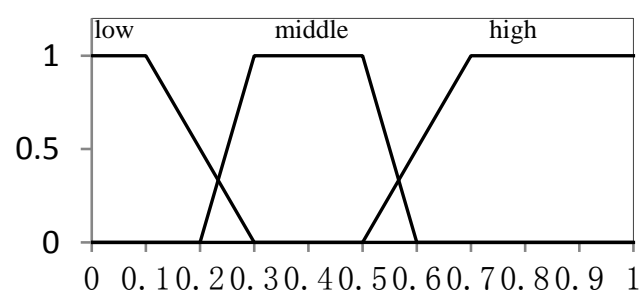

Fig. 6. Motor Braking Torque Ratio Coefficient Membership Function

Table 1. Fuzzy Control Rules

\begin{tabular}{|l|lll|}
\hline \multicolumn{1}{|c|}{ speed } & high & middle & low \\
\hline high & high & high & low \\
middle & high & middle & low \\
low & high & middle & low \\
\hline
\end{tabular}

\section{The Formulation of Dynamic Coordinated Control Strategy}

In the process of braking, the fuzzy controller combined with the vehicle information, the appropriate mode of braking is selected. In the switching process of braking mode, due to the different dynamic response characteristics of motor, electro hydraulic retarder and mechanical brake system, the actual total braking torque will produce fluctuation and is different from the required braking torque of the driver, affecting the braking feel of the driver and braking comfort. For the situation of the braking force fluctuation when the mode of electric drive tracked vehicle brake switches, this paper aims at minimizing fluctuations caused by brake mode switch and basing on dynamic response characteristics of three kinds of brake components to develop dynamic coordinated control strategy.

The dynamic coordinated control strategy is shown in Fig. 7. Two degree of freedom dynamic coordinated control strategy of feed forward and feedback is adopted. The feedback controller is designed to reduce the fluctuation of the disturbance, so as to ensure the stability and robustness of the system. The feed forward controller is able to guarantee the system response characteristics and the matching characteristics [9]. 


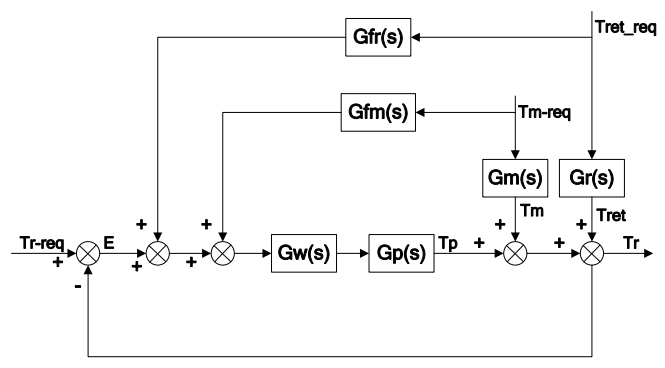

Fig. 7. Block Diagram of Dynamic Coordination Control System

\section{The Establishment of Real Time Simulation Model}

\section{Vehicle Dynamics Model}

For the electric drive tracked vehicle, the vehicle dynamics equation on the horizontal pavement is:

$$
\left\{\begin{array}{l}
F_{b}+F_{w}+F_{f}=\delta m \frac{d v}{d t} \\
F_{\mathrm{b}}=F_{\text {mech }}+F_{\text {elec }}+F_{r e t} \\
\left.v\right|_{\mathrm{t}=0}=v_{0},\left.v\right|_{\mathrm{t}=t_{1}}=0
\end{array}\right.
$$

$F_{f}$ : rolling resistance; $F_{w}$ :air resistance; $F_{b}$ :the composite braking force; $F_{\text {mech }}$ : mechanical braking force; $F_{\text {elec }}$ :the motor braking force; $F_{\text {ret }}$ :electro hydraulic retarder braking force; $F_{\text {ret }}:$ mass increase coefficient, choose 1.3 ; m: mass of the vehicle; $v_{0}$ : the initial speed of braking; $t_{1}$ :braking time.

\section{Braking Pedal Model}

The driver's braking intention is realized through the angle of the brake pedal; the greater the angle of the pedal is, the greater the braking intensity is. The work scope of the braking pedal is $\left[0,45^{\circ}\right]$, when the pedal passes through the idle stroke $\alpha_{0}$,considering the next trip being conscious operation of driver; when the displacement of the angle of brake pedal is larger than $\alpha_{1}$, vehicle comes into the situation of emergency braking. According to the driver's operating habits, select $\alpha_{0}$ for $5^{\circ}, \alpha_{1}$ for $35^{\circ}$.

\section{Motor Model}

Based on the data of bench test and reference [7], the characteristic curve of the motor has the ideal driving-braking characteristic, that is, the motor runs at constant torque area. Based on the characteristic curve of the motor, the output torque of the motor can be derived:

$$
T_{m}= \begin{cases}0 & , 0 \leq n \leq n_{\min } \\ 9549 \frac{P_{m}}{n_{0}} & , \mathrm{n}_{\text {min }}<n \leq n_{0} \\ 9549 \frac{P_{m}}{n} & , n_{0}<n \leq n_{\max } \\ 0 & , n>n_{\max }\end{cases}
$$

$P_{m}$ :motor power, when the motor works at the state of driving, the motor power is positive; when the motor works at the state of braking, the motor power is negative; $n_{0}$ :the rotation speed of the motor at the point of rated power; $\mathrm{n}_{\text {min }}$ : the minimum stable rotation speed of the motor; $n_{\max }$ :the maximum stable rotation speed of the motor. 


\section{Electro Hydraulic Retarder Model}

Doubly salient electro hydraulic retarder is a special kind of eddy current retarder, similar to the working principle of electric eddy current retarder. The relationship between braking torque and rotation speed of electro hydraulic retarder is obtained by experiments. Test data is shown in Fig. 8 . The model of electro hydraulic retarder is established by the look-up table.

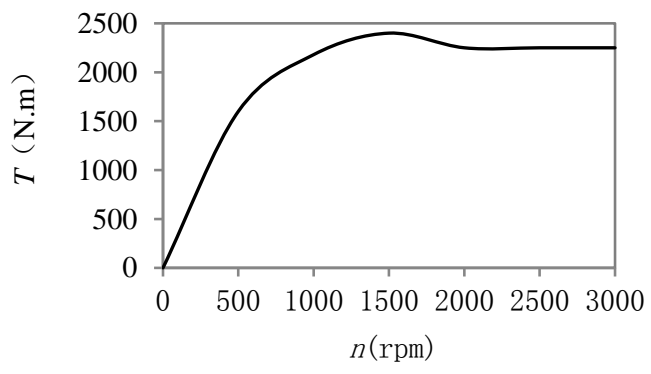

Fig. 8. Braking Characteristics of Electro Hydraulic Retarder

\section{Mechanical Braking Model}

Braking characteristics [10] of mechanical brake are as follows:

$$
T_{\mathrm{fc}}=\mu \cdot K_{n} \cdot F \cdot r_{e} \cdot Z
$$

$\mu$ : friction coefficient; $F$ : the normal pressing force of the friction plate; $r_{e}:$ the equivalent radius; $K_{n}$ : the reduction coefficient of the pressing force of frictional couple; $Z$ :the number of frictional couples.

Sufficient braking force can be provided by brake, when the adhesion force of surface is greater or equal to the mechanical braking force, the mechanical brake can play the maximum braking effect. So take the ground adhesion force as the maximum braking force of the mechanical brake, that is:

$$
F_{m}=\frac{T_{f c}}{R} \leq F_{m} \max =\varphi m g
$$

$\varphi$ : adhesion coefficient on road surface, $\varphi=0.4 ; \quad F_{m}$ max :the maximum braking force of the mechanical brake; $R:$ the radius of active wheel; $g$ : acceleration of gravity.

\section{Results and Analysis of Simulation}

In order to accurately make analysis of the braking performance of electric drive high speed tracked vehicle mechanics-motor-retarder composite braking and verify the mechanics-motor-retarder composite braking control strategy, "driver-controller" [11] in the ring of the electric drive high speed tracked vehicle real-time simulation system is built to carry out the real-time simulation experiments.

\section{Analysis of 32km/h Emergency Braking Simulation}

The vehicle will be accelerated to $32 \mathrm{~km} / \mathrm{h}$; the pedal is stepped down at the angle of 45 degrees; the system determines the braking mode should be an emergency braking; results of simulation are shown in Fig. 9 to 12. 


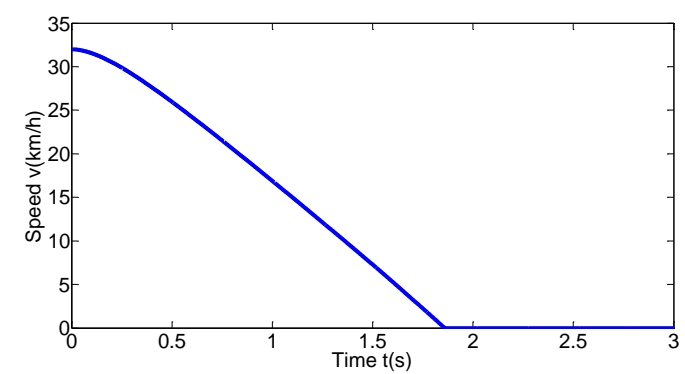

Fig. 9. Speed of Vehicle Curve

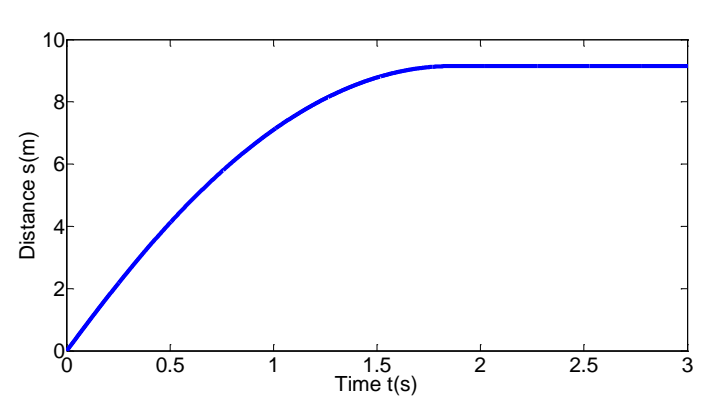

Fig. 11. Braking Distance Curve

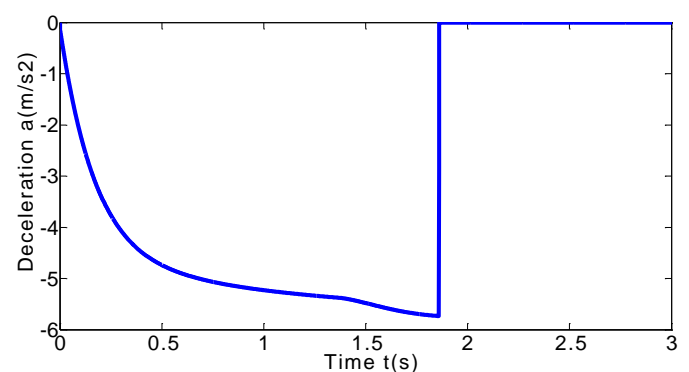

Fig. 10. Braking Deceleration Curve

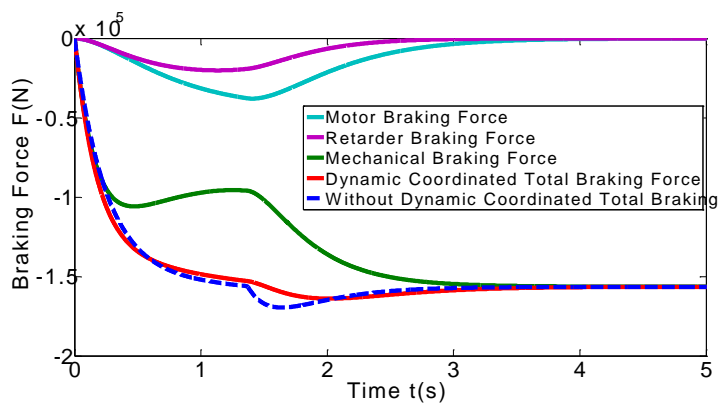

Fig. 12. Braking Force Curve

From the Figure show that the emergency braking deceleration is stable at around $-5.5 \mathrm{~m} / \mathrm{s} 2$; time is $1.82 \mathrm{~s}$; braking distance is $9.2 \mathrm{~m}$; all of them meet the regulations of $32 \mathrm{~km} / \mathrm{h}$ emergency braking distance of the vehicle less than $12 \mathrm{~m}$. As is shown in Fig. 12, when the speed is higher than $10 \mathrm{~km} / \mathrm{h}$, vehicles use the mode of mechanics-motor-retarder composite braking, at this time giving priority to the use of brake motor as much as possible; when the braking torque of the motor cannot meet the requirement, the insufficient part is supplied by the electro hydraulic retarder, and still not insufficient part is provided by the mechanical brakes, and the sum of the three is the total braking force; when the speed is lower than $10 \mathrm{~km} / \mathrm{h}(1.35 \mathrm{~s})$, total braking force are provided by mechanical brakes. And comparing the dynamic coordination with without dynamic coordination, the total braking force is more stable and the response speed is faster. The experimental results show that the control strategy is effective.

\section{Simulation Analysis of 70km/h Composite Braking}

The vehicle will be accelerated to $70 \mathrm{~km} / \mathrm{h}$; the pedal is stepped down at the angle of 28 degrees; the system determines the braking mode should be composite braking, results of simulation are shown in Fig. 13 to 16.

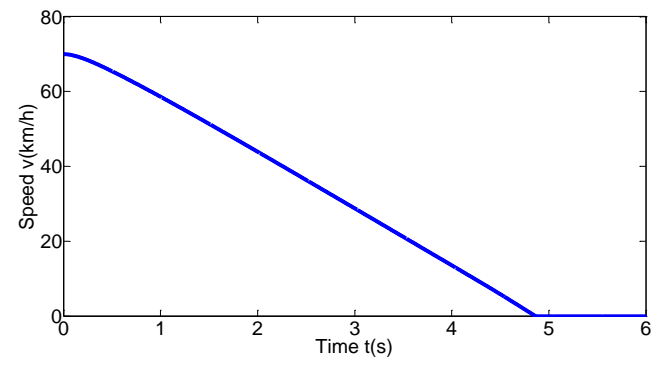

Fig. 13. Vehicle Speed Curve

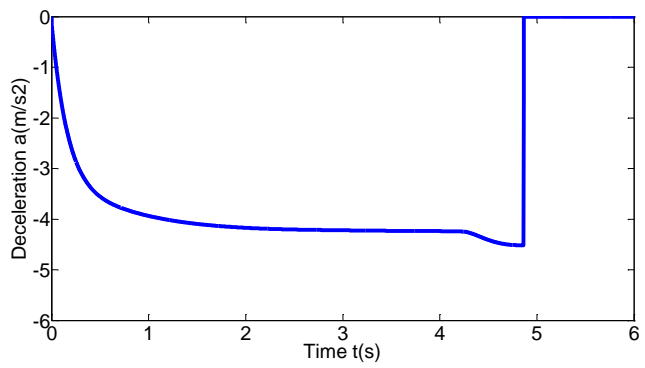

Fig. 14. Braking Deceleration 


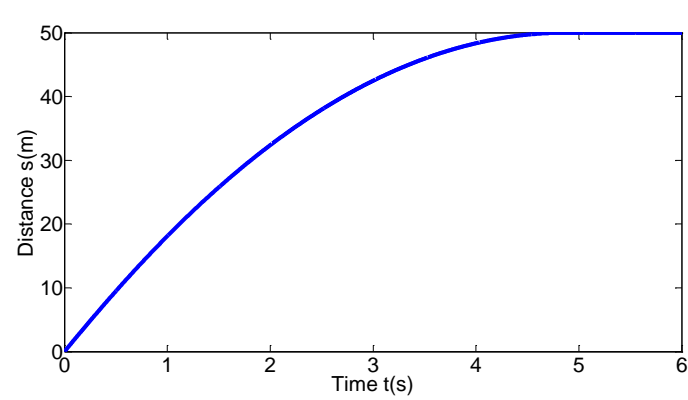

Fig. 15. Braking Distance Curve

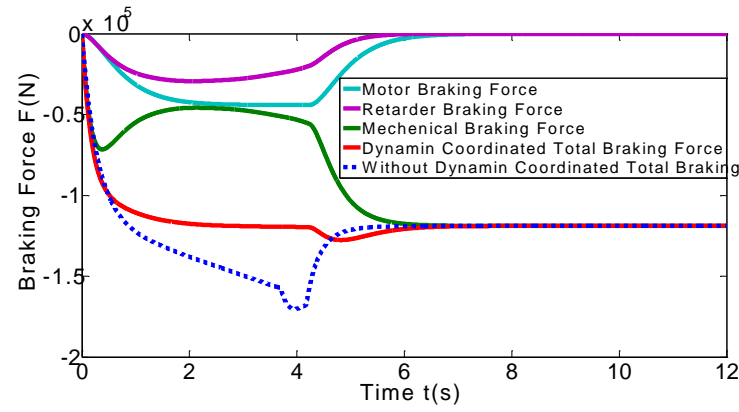

Fig. 16. Braking Force Curve

From the Figures above show that the braking time is $4.9 \mathrm{~s}$; the braking deceleration is stable near $-4.4 \mathrm{~m} / \mathrm{s} 2$; the distance of the $70 \mathrm{~km} / \mathrm{h}$ composite braking is $50 \mathrm{~m}$; all of them meet the braking requirements. As is shown in Fig. 16, when the speed is higher than $16 \mathrm{~km} / \mathrm{h}$, motor braking accounted for a higher proportion; when the speed is lower than $16 \mathrm{~km} / \mathrm{h}$, the proportion of mechanical braking increases gradually; when the speed of vehicle is less than $10 \mathrm{~km} / \mathrm{h}$, braking torque is completely provided by the mechanical brake.

\section{Simulation Analysis of $85 \mathrm{~km} / \mathrm{h}$ Gradual Progress Braking}

The vehicle will be accelerated to $85 \mathrm{~km} / \mathrm{h}$, with a speed of 3 degrees per second to step down the braking pedal, and the simulation results are shown in Fig. 17 to 20.

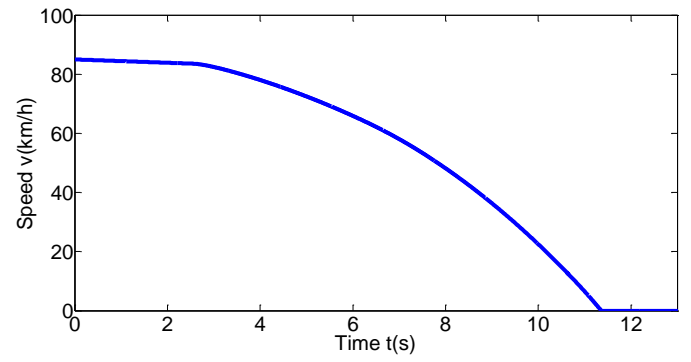

Fig. 17. Vehicle Speed Curve

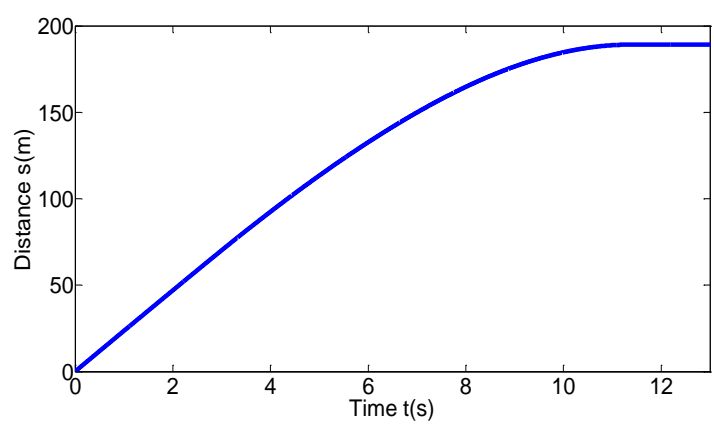

Fig. 19. Braking Distance Curve

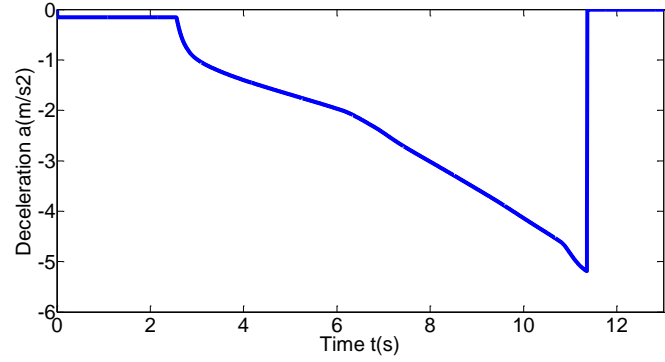

Fig. 18. Braking Deceleration

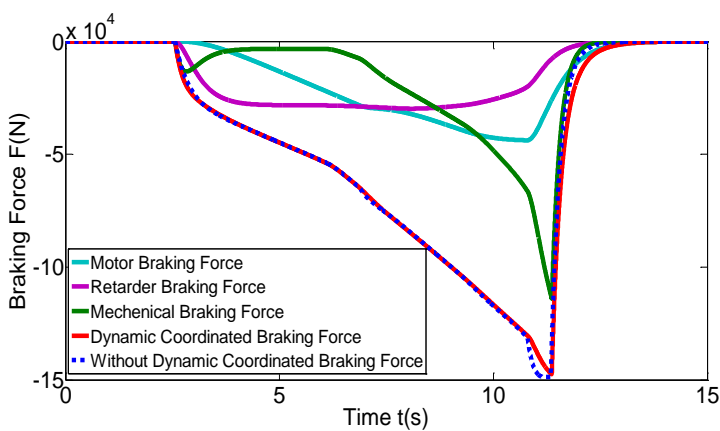

Fig. 20. Braking Force Curve

As the pictures above show, the braking time of $85 \mathrm{~km} / \mathrm{h}$ gradual progress braking is $11.4 \mathrm{~s}$; the braking distance is $192 \mathrm{~m}$; the braking deceleration is increasing with the demand of braking. As is shown in Fig. 20, when the brake pedal treads air travel (about 2.5s), it become effective, then the speed is high, but the demand of braking is small, braking force provided by motor and electro hydraulic retarder; when the speed of vehicle downhill to $80 \mathrm{~km} / \mathrm{h}$, the mechanical brake began to play a role and the ratio of mechanical braking force increased gradually; when the speed of vehicle downhill to $10 \mathrm{~km} / \mathrm{h}$, braking force is supplied completely by mechanical braking force until speed dropped 0. 


\section{Conclusion}

In the light of the braking requirement of electric drive high speed tracked vehicle, carried out the research for the first time of mechanics-motor-retarder composite braking; proposed braking force proportional allocation strategy based on fuzzy control of the motor; established the model of realtime dynamic simulation system. The results of simulation show that:

(1) the proposed strategy of mechanics-motor-retarder composite braking have made full use of the advantages of the three components; improved the stability of the brake; can meet the braking requirements of high speed tracked vehicles well.

(2) In this paper, the control strategy is compared with the strategy without dynamic coordination control, shorter response time and smaller fluctuation, which has improved the dynamic performance of the system. However, fluctuation is still in existence. In future work, dynamic coordinated control should be strengthened.

\section{References}

[1] HE Ren, WANG Yong-tao, ZHAO Ying-sheng. Performance Simulation Analysis of the United Brake System of Automobiles [J]. Acta Armamentarii, 2007, 28(10):1153-1158.

[2] ZHAO Guang-jun, LV Jian-gang, SONG Bin, et al. Fuzzy control of combined braking system in hydraulic hybrid tracked vehicle [J]. Control Theory \& Applications, 2010, 27(12): 1674-1680.

[3] LI Feng, GU Zhong-li, LIU Xiao-xing. Study On Electric-mechanical Composite Braking Strategy Based on Fuzzy Rules for Hybrid Tracked Vehicle [J].Chinese Journal of Automotive Engineering, 2012.2(3): 221-227.

[4] Numasato H, Tomizuka M. Settling Control and Performance of a Dual-Actuator [J]. IEEE/ASME Transaction on Mechatronics, 2008, 8(4): 431 -438.

[5] TAIZO SAKAMOTO. Cooperative Control of Full Electric Braking System with Independently Driven Four Wheels[C]//9th IEEE International Workshop on Advanced Motion Control.2008: 373 -381 .

[6] ZHOU Qiu-jun, GU Zhong-li, SUN Feng-chun. Simulation of Electro mechanical Braking System in Electric-drive Tracked Vehicle [J].Computer Simulation, 2005, 22(11): 226-229.

[7]SHANG Ming-li. Research on Regenerative Braking and Stability Integration Control Algorithm for Hybrid Electric Vehicle [D]. Jilin: Ji Lin University, 2011.

[8] WANG Cong. Structural Optimization of Retarder with a Structure of Two Salient Poles [D]. Bei Jing: Beijing University of Technology, 2014.

[9] ZHANG Ti-huan. Study on the Coordinated Control Algorithm of Braking Force for HEV Bus [J]. Chang Chun: Ji Lin University, 2011.

[10] YAN Qing-dong, ZHANG Lian-di, ZHAO Yu-qin, et al. Tank Structure and Design [M]. Beijing: Beijing Institute of Technology Press, 2007.

[11] ZOU Yuan, SUN Feng-chun, ZHANG Cheng-ning. Electric tracked vehicle real-time simulation of dual-motor driving control with driver-global controller in-loop [J]. Chinese Journal of Mechanical Engineering, 2007, 43(3): 193-198. 